\title{
A new species of the genus Gonatopus Ljungh from the USA (Hymenoptera, Dryinidae)
}

\author{
Adalgisa Guglielmino', Massimo Olmi², Alessandro Marletta ${ }^{3}$, Stefano Speranza' \\ I Department of Agriculture and Forestry Sciences (DAFNE), University of Tuscia, Viterbo, Italy 2 Tropical \\ Entomology Research Center, Viterbo, Italy 3 Department of Biological, Geological and Environmental Scien- \\ ces, Animal Biology section, University of Catania, Catania, Italy
}

Corresponding author: Massimo Olmi (olmimassimo@gmail.com)

Academic editor: M. Ohl | Received 11 February 2018 | Accepted 20 March 2018 | Published 29 March 2018

http://zoobank.org/40EC0361-35F7-442F-BABB-93F63DDDEFBF

Citation: Guglielmino A, Olmi M, Marletta A, Speranza S (2018) A new species of the genus Gonatopus Ljungh from the USA (Hymenoptera, Dryinidae). ZooKeys 747: 63-69. https://doi.org/10.3897/zookeys.747.24399

\begin{abstract}
A new species of Gonatopus Ljungh, 1810 is described from the USA, Florida: G. jacki sp. n. Morphologically, the new species is similar to G. ashmeadi Kieffer, 1905 and G. agropyrus Fenton, 1921, but it is distinguished by the different shape of the mesoscutum (very slender in G. jacki; broader in G.ashmeadi and G.agropyrus). Published identification keys to the Nearctic species of Gonatopus are modified to include the new species.
\end{abstract}

\section{Keywords}

Chrysidoidea, Florida, Gonatopodinae, key, Nearctic region, taxonomy

\section{Introduction}

Based on all known host records, Dryinidae (Hymenoptera, Chrysidoidea) are parasitoids of Auchenorrhyncha (Hemiptera) (Guglielmino et al. 2013). However, the biology of this group of small wasps is still poorly known (Guglielmino et al. 2006, 2008, 2015). Gonatopus Ljungh, 1810 is a genus that is present in all zoogeographical regions (Olmi 1984; Guglielmino and Virla 1998; Guglielmino and Bückle 2003, 2010; Xu 
et al. 2013; Olmi and Virla 2014; Olmi and Xu 2015). In total 441 species have been described from all continents (Guglielmino and Olmi 2014; Olmi and Xu 2015) and the genus was revised at world level by Olmi $(1984,1991)$, and more recently in the Oriental, Neotropical and Eastern Palaearctic regions by Xu et al. (2013), Olmi and Virla (2014) and Olmi and Xu (2015),

The species of Gonatopus inhabiting the Nearctic region were studied by Olmi (1984, 1987, 1992, 1993a, 1993b, 1995, 2003). More recently, Olmi and Guglielmino (2013) described one further new species from the USA, Arkansas (Gonatopus rileyi Olmi \& Guglielmino). In total, 51 Gonatopus species have been described from the Nearctic region (Olmi 1984, 1987, 1992, 1993a, 1993b, 1995, 2003; Olmi and Guglielmino 2013).

Gonatopus species are parasitoids of leafhoppers and planthoppers belonging to the Acanaloniidae, Cicadellidae, Delphacidae, Dictyopharidae, Flatidae, Issidae, Lophopidae, Meenoplidae, Tropiduchidae (Guglielmino et al. 2013). As in almost all dryinids, females of Gonatopus have a chelate protarsus. Chelae are used to capture and restrain the host during ovipositions and hostfeeding (Olmi 1984, 1994).

In 2015, additional specimens of Gonatopus from the USA were examined and the new species found is described herein.

\section{Materials and methods}

The descriptions follow the terminology used by Olmi (1984), Olmi and Guglielmino (2010), and Olmi and Virla (2014). The measurements reported are relative, except for the total length (head, except antennae, to abdominal tip), which is expressed in millimeters. In the descriptions, POL is the distance between the inner edges of the two lateral ocelli; $\mathbf{O L}$ is the distance between the inner edges of a lateral ocellus and the median ocellus; OOL is the distance from the outer edge of a lateral ocellus to the compound eye; OPL is the distance from the posterior edge of a lateral ocellus to the occipital carina; and TL is the distance from the posterior edge of an eye to the occipital carina. The term "metapectal-propodeal complex" is here used in the sense of Kawada et al. (2015). It corresponds to the term "propodeum" sensu Olmi (1984, 1994), Xu et al. (2013), Olmi and Virla (2014), and Olmi and Xu (2015).

The types of all Nearctic and Neotropical species of Gonatopus have been previously examined by the authors.

The material studied in this paper is deposited in the Department of Agriculture and Forestry Sciences, University of Tuscia, Viterbo, Italy (MOLC).

The description of the new species is based on the study of a single specimen. The authors are aware that descriptions of new taxa should normally be based on more individuals. However, Dryinidae are so rare that it is uncommon to collect more than one specimen of each species. In addition, on the basis of the experience and knowledge of the authors, the new species is sufficiently delimited by unique characters to justify its description. 


\section{Taxonomy}

\section{Genus Gonatopus Ljungh, 1810}

Gonatopus Ljungh, 1810: 161. Type species: Gonatopus formicarius Ljungh, 1810, by monotypy.

Diagnosis. Female: Apterous or macropterous; palpal formula 3/2, 4/2, 4/3, 5/2, 5/3, or 6/3; pronotum crossed or not by transverse furrow; enlarged claw with distal apex pointed and with one large or small subapical tooth (occasionally subapical tooth absent, then enlarged claw with distal group of lamellae); in macropterous forms, protarsomere $\mathrm{V}$ with more than 20 lamellae; tibial spurs 1/0/1. Male: Fully winged; occipital carina absent or incomplete (in this last case, present behind and shortly on sides of posterior ocelli); occiput concave; temple present; palpal formula $3 / 2,4 / 2,4 / 3,5 / 2,5 / 3$, or $6 / 3$; tibial spurs $1 / 1 / 2$.

\section{Gonatopus jacki sp. n.}

http://zoobank.org/58D11919-7B91-4A07-87CA-E94B23BCE001

Diagnosis. Female apterous (Fig. 1A, B); palpal formula 5/2; pronotum crossed by deep transverse furrow (Fig. 1B); mesoscutum without lateral pointed apophyses (Fig. 1A); metanotum not hollow behind mesoscutellum (Fig. 1B); meso-metapleural suture obsolete; first abdominal tergum strongly transversely striate (Fig. 1A); enlarged claw with peg-like hairs and one small subapical tooth (Fig. 2A).

Description. Female. Apterous (Fig. 1A, B); length $3.4 \mathrm{~mm}$. Head brown, except mandible, clypeus, region of face between antennal toruli and two short frontal stripes along orbits yellow-whitish; antenna brown, except antennomere 10 whitish; mesosoma and metasoma black; legs brown, except metatrochanter testaceous. Antenna clavate; antennomeres in following proportions: 9:6:14:10:10:9:8:8:7:10. Head excavated, shiny, not sculptured; frontal line complete; occipital carina absent; POL $=1 ; \mathrm{OL}=2 ; \mathrm{OOL}=8$; greatest breadth of posterior ocellus about as long as POL. Palpal formula 5/2. Mesosoma with long sparse setae. Pronotum shiny, unsculptured, crossed by deep transverse impression. Mesoscutum slender (Fig. 1A), dull, granulated, laterally without pointed apophyses (Fig. 1A). Mesoscutellum very small, flat, not sculptured. Metanotum flat, transversely striate, not hollow behind mesoscutellum (Fig. 1B). Metapectal-propodeal complex shiny, with metapostonotum not sculptured; first abdominal tergum transversely striate. Mesopleuron and metapleuron granulated and transversely striate. Meso-metapleural suture obsolete. Protarsomeres in following proportions: 13:2:4:17:26. Protarsomere III produced into hook. Enlarged claw (Fig. 2A) with one small subapical tooth and nine peg-like hairs + one bristle. Protarsomere $\mathrm{V}$ (Fig. 2A) with two rows of $4+22$ lamellae situated in distal half; distal apex with approximately eleven lamellae. Tibial spurs $1 / 0 / 1$.

Male. Unknown. 


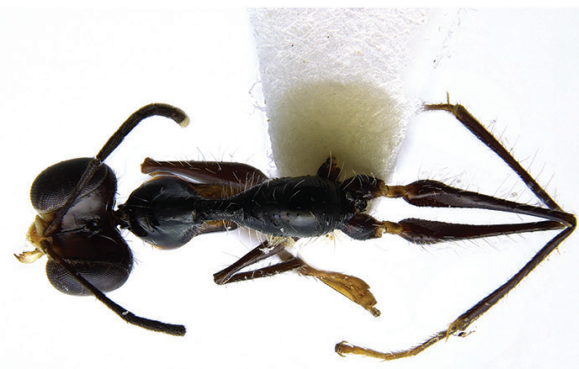

A

B
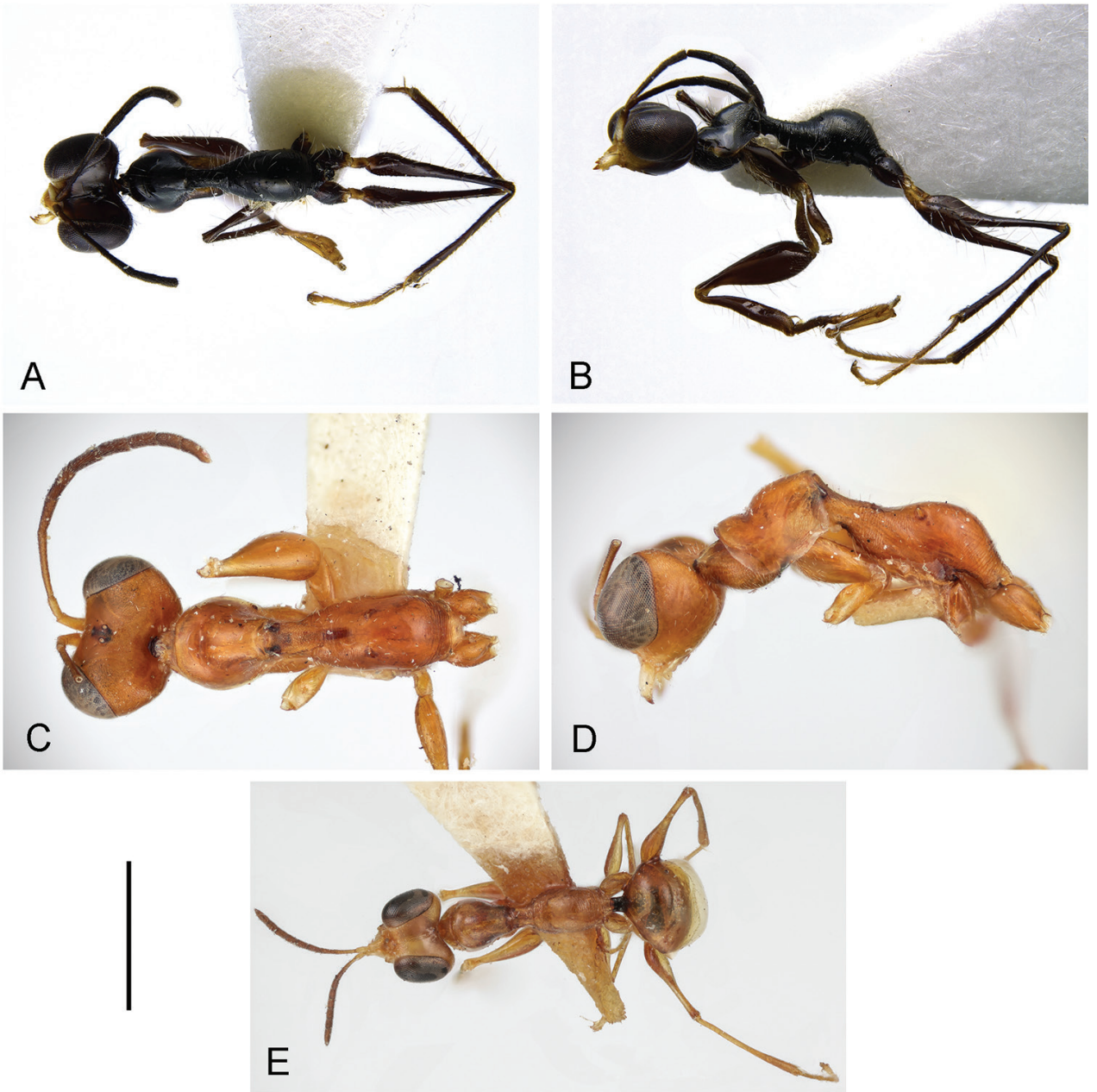

Figure I.A, B Gonatopus jacki sp. n., holotype: head and mesosoma in dorsal (A) and lateral (B) view. Gonatopus ashmeadi holotype: head and mesosoma in dorsal (C) and lateral (D) view; Gonatopus agropyrus holotype in dorsal view (E). Scale bars: $1.38 \mathrm{~mm}(\mathbf{A}) ; 1.54 \mathrm{~mm}(\mathbf{B}) ; 0.51 \mathrm{~mm}(\mathbf{C}, \mathbf{D}) ; 1.09 \mathrm{~mm}(\mathbf{E})$.

Material examined. Holotype: a female from the USA, Florida, Sarasota Co., Turtle Beach, $27.217^{\circ} \mathrm{N} 82.517^{\circ} \mathrm{W} \pm 2 \mathrm{~km}, 5 \mathrm{~m}, 30$.xii.1989, beach margin, No 2601S, John T. Longino leg. (MOLC).

Distribution. USA.

Hosts. Unknown.

Etymology. The species is named after the collector, John T. (Jack) Longino.

Remarks. The new species is similar to G. ashmeadi Kieffer in Kieffer \& Marshall, 1905 and G. agropyrus Fenton, 1921, by having head mostly brown, labial palpus bisegmented, mesoscum with no lateral pointed apophyses, meso-metapleural suture obsolete, first abdominal tergum transversely striate, protarsomere I shorter than IV, protarsomere $\mathrm{V}$ with lamellae situated in distal half. The main difference among $G$. jacki 


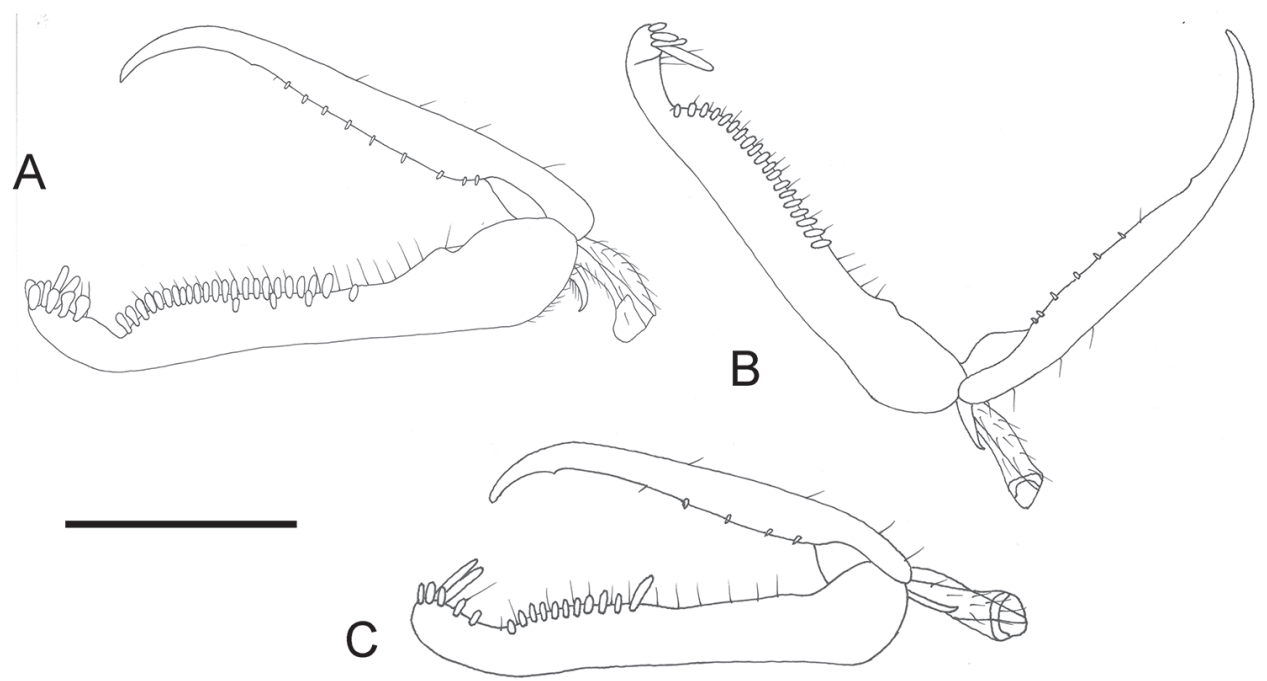

Figure 2. A Gonatopus jacki sp. n., chela of holotype. B Gonatopus ashmeadi Kieffer: chela of female from USA, Georgia, Spring Creek C Gonatopus agropyrus Fenton: chela of female from USA, Kentucky, Lexington. Scale bars: $0.16 \mathrm{~mm}(\mathbf{A}) ; 0.13 \mathrm{~mm}(\mathbf{B}, \mathbf{C})$.

and the other two species is in the mesoscutum shape: very slender in G. jacki (Fig. 1A); broader in G.ashmeadi (Fig. 1C) and G. agropyrus (Fig. 1E). The comparison of the holotypes of the above three species shows also a difference regarding the colour: mostly black in G. jacki (Fig. 1A, B), yellow-testaceous in G. agropyrus (Fig. 1E) and testaceousferruginous in G. ashmeadi (Fig. 1C, D). However, these differences are not significant, because the colour can be very variable, so that mostly black specimens are known in both $G$. agropyrus and G. ashmeadi. Following the description of G. jacki, the key to the females of the Nearctic species of Gonatopus group 7 published by Olmi (1993b) can be modified by replacing couplet 14 as follows:

14 Scutum very slender (Fig. 1A) G. jacki sp. n. Scutum broader (Fig. 1C, E) $14^{*}$

14* Protarsomere V with lamellae of approximately same length (Fig. 2B) G. ashmeadi Kieffer

- $\quad$ Protarsomere V with lamellae much longer near base (Fig. 2C)

.G. agropyrus Fenton

\section{Conclusions}

Olmi (1984, 1987, 1992, 1993a, 1993b, 1995, 2003) and Olmi and Guglielmino (2013) listed 51 Gonatopus from the Nearctic region. With the description of the above new species the number of species now known in the USA is 52 . In comparison with the 
135 species listed in Mexico (Moya Raygoza and Olmi 2010), the dryinid fauna of the USA is poorly known, as is that of Canada (18 listed species). A similar situation exists also regarding the hosts: they are known only in 26 species (Guglielmino et al. 2013).

\section{Acknowledgments}

Many thanks to John T. (Jack) Longino, University of Utah, Salt Lake City, for sending the specimen of Gonatopus described in the present paper. We are also grateful to Sean Brady and Karolyn Darrow for sending multifocal photos of holotypes deposited in the Smithsonian Institution, Washington, DC, USA. Many thanks to Robert S. Copeland (ICIPE, Nairobi, Kenya) for checking the English language of this paper.

\section{References}

Fenton FA (1921) New parasitic Hymenoptera of the subfamily Anteoninae (Dryinidae). The Canadian Entomologist 58: 70-71. https://doi.org/10.4039/Ent5370-3

Guglielmino A, Bückle C (2003) Description of larval instars of Neodryinus typhlocybae (Ashmead, 1893) (Hymenoptera Dryinidae), with remarks on its biology. Mitteilungen aus dem Museum für Naturkunde in Berlin-Deutsche Entomologische Zeitschrift 50: 143-150. https://doi.org/10.1002/mmnd.20030500114

Guglielmino A, Bückle C (2010) Description of larval instars of Mystrophorus formicaeformis Ruthe (Hymenoptera: Dryinidae). Zootaxa 2602: 57-66.

Guglielmino A, Bückle C, Moya-Raygoza G (2006) Description of the larval instars of Gonatopus bartletti Olmi, 1984 (Hymenoptera: Dryinidae). Zootaxa 1226: 51-60.

Guglielmino A, Olmi M (2014) Revision of the Afrotropical species of Gonatopus group 3 (Hymenoptera: Dryinidae), with description of a new species from Ghana. Zootaxa 3802: 35-50. https://doi.org/10.11646/zootaxa.3802.1.3

Guglielmino A, Olmi M, Bückle C (2013) An updated host-parasite catalogue of world Dryinidae (Hymenoptera: Chrysidoidea). Zootaxa 3740: 1-113. https://doi.org/10.11646/ zootaxa.3740.1.1

Guglielmino A, Parise G, Bückle C (2015) Description of larval instars of Dryinus tarraconensis Marshall, 1868 and Gonatopus baeticus (Ceballos, 1927) (Hymenoptera: Chrysidoidea: Dryinidae), parasitoids of the genus Dictyophara Germar (Hemiptera: Auchenorrhyncha: Dictyopharidae). Zootaxa 4032: 42-54. https://doi.org/10.11646/zootaxa.4032.1.2

Guglielmino A, Virla EG (1998) Postembryonic development of Gonatopus lunatus Klug (Hymenoptera: Dryinidae: Gonatopodinae), with remarks on its biology. Annales de la Société entomologique de France (NS) 34: 321-333.

Guglielmino A, Virla EG, Olmi M, Moya-Raygoza G, Vollaro M (2008) Parasitization behaviour and postembryonic development in the subfamily Gonatopodinae. Bulletin of Insectology 61: 211 . 
Kawada R, Lanes GO, Azevedo CO (2015) Evolution of metapostnotum in flat wasps (Hymenoptera, Bethylidae): implications for homology assessments in Chrysidoidea. PLoS ONE 10(10): e0140051. https://doi.org/10.1371/journal.pone.0140051

Kieffer JJ, Marshall TA (1905) Proctotrypidae. In: André E (Ed.) Species des Hyménoptères d'Europe et d'Algerie 9. Hermann, Paris, 65-288.

Ljungh SJ (1810) Gonatopus, novum insectorum genus. Beiträge zur Naturkunde 2: 161-163. Moya Raygoza G, Olmi M (2010) A catalogue of Dryinidae of Mexico, with descriptions of the opposite sexes of some species (Hymenoptera Chrysidoidea). Frustula Entomologica (NS) 31[2008]: 77-112.

Olmi M (1984) A revision of the Dryinidae (Hymenoptera). Memoirs of the American Entomological Institute 37: 1-1913.

Olmi M (1987) New species of Dryinidae (Hymenoptera, Chrysidoidea). Fragmenta Entomologica 19: 371-456.

Olmi M (1991) Supplement to the revision of the world Dryinidae (Hymenoptera Chrysidoidea). Frustula entomologica (1989, N.S.) 12: 109-395.

Olmi M (1992) Contribution to the knowledge of the Gonatopodinae (Hymenoptera Dryinidae). Bollettino dell'Istituto di Entomologia dell'Università di Bologna 46: 109-122.

Olmi M (1993a) A new generic classification for Thaumatodryininae, Dryininae and Gonatopodinae, with descriptions of new species (Hymenoptera Dryinidae). Bollettino di Zoologia agraria e di Bachicoltura Ser. II, 25: 57-89.

Olmi M (1993b) Descriptions of new taxa of Dryinidae (Hymenoptera Chrysidoidea). Frustula entomologica (1992, N.S.) 15: 19-62.

Olmi M (1994) The Dryinidae and Embolemidae (Hymenoptera: Chrysidoidea) of Fennoscandia and Denmark (Fauna Entomologica Scandinavica 30). E.J. Brill, Leiden, Netherlands, 100 pp.

Olmi M (1995) Contribution to the knowledge of the world Dryinidae (Hymenoptera Chrysidoidea). Phytophaga 6: 3-54.

Olmi M (2003) A contribution to the knowledge of Dryinidae (Hymenoptera Chrysidoidea). Frustula entomologica (NS) 24[2001]: 21-49.

Olmi M, Guglielmino A (2010) Description of Erwiniinae, new subfamily of Dryinidae from Ecuador (Hymenoptera: Chrysidoidea). Zootaxa 2605: 56-62.

Olmi M, Guglielmino A (2013) Description of Gonatopus rileyi sp. nov. from Arkansas (Hymenoptera: Dryinidae). The Pan-Pacific Entomologist 89: 79-83. https://doi.org/10.3956/2012-60.1

Olmi M, Virla EG (2014) Dryinidae of the Neotropical region (Hymenoptera: Chrysidoidea). Zootaxa 3792: 1-534. https://doi.org/10.11646/zootaxa.3792.2.1

Olmi M, Xu Z (2015) Dryinidae of the Eastern Palaearctic region. Zootaxa 3996: 1-253. https://doi.org/10.11646/zootaxa.3996.1.1

Xu Z, Olmi M, He J (2013) Dryinidae of the Oriental region (Hymenoptera: Chrysidoidea). Zootaxa 3614: 1-460. https://doi.org/10.11646/zootaxa.3900.1.1 